\title{
Should I stay or should I switch? An analysis of transitions between modes of vocational education and training ${ }^{\text {th }}$
}

\author{
Joelle Latina ${ }^{\mathrm{a}, \mathrm{b}, *}$ \\ ${ }^{a}$ Haute Ecole de Gestion, HES-SO, University of Applied Sciences Western Switzerland, \\ 17 Rue de la Tambourine 1227 Carouge, Switzerland \\ ${ }^{b}$ NCCR LIVES "Overcoming vulnerability: life course perspectives"
}

\begin{abstract}
How established is the horizontal permeability between modes of vocational education and training (VET) in Switzerland? Formally encouraged by the Swiss law on VET, horizontal permeability refers to transitions across VET modes, i.e., between dual and school-based VET. This paper first discusses why horizontal permeability is indeed relevant and then empirically examines the horizontal permeability of the Swiss VET system for a given occupation - commercial VET. The latter is the largest VET domain in Switzerland and, importantly, a domain in which school-based VET is well established. The empirical analysis uses panel data following a cohort for over 10 years in the Canton of Geneva. Results show that going from school-based to dual VET within commercial VET increases chances to earn a qualification, however students changing modes lose half a year in the process. These findings suggest that, at least in commercial VET, horizontal permeability is only partial.
\end{abstract}

Keywords: dual VET; school-based VET; commercial VET; horizontal

\footnotetext{
対I am most grateful to José V. Ramirez and Paul Ryan for many helpful discussions and comments. I would also like to thank Mr Erwin Fisher from the cantonal training office (OFPC) for helping me with the statistics on commercial VET in Geneva. Thanks also go to Jacqueline Pfenninger for her editing skills. Many thanks to two anonymous reviewers for their helpful comments and suggestions. Finally, I thank the Canton of Geneva, the Cantonal Department of Public Education (DIP) and its Research Department in Education (SRED) for providing the data. Funding provided by the State Secretariat for Education, Research and Innovation (SERI) under grant number $<$ BB.2010.0098 $>$ and by the Haute Ecole de Gestion de Genève is duly acknowledged. This piece of research is part of the research conducted at the Swiss National Center of Competence in Research LIVES-Overcoming vulnerability: life course perspectives, which is financed by the Swiss National Science Foundation. Any remaining error is mine.

${ }^{*}$ Corresponding author. Tel.: +4122 3881870 Fax: +4122 3881701

Email address: joelle.latina@hesge.ch (Joelle Latina)
} 
permeability, correlated random effect models. 


\section{Introduction}

Switzerland is considered, amongst others, a traditional dual vocational education and training (VET) country: on average at the country level, roughly two third of each cohort follow this path (SERI 2016). Dual VET or apprenticeship programs ${ }^{1}$ 'comprise both work-based training and formal education, in most countries at upper-secondary level, and lead to a qualification in an intermediate skill' (Wolter and Ryan 2011, 523). Admission to a dual VET program is conditioned on finding a contract with a training firm and is thus considered a market-based mode of education. However, all successful dual VET systems are strongly dependent on a (variable) set of institutions, such as government regulation, employer representation or social partnership (Busemeyer and Trampusch [2011], Deissinger and Gonon [2016]).

The market for dual VET positions fluctuates each year due to both structural and cyclical factors. Concerning structural factors, the growing importance of the service sector, in which dual VET is less established than in the manufacturing sector (Culpepper and Thelen 2008), and the smaller share of firms willing to train have both led to a deficit of dual VET positions from 1995 and onwards (Schweri and Mueller [2007], Trampusch [2010]). This deficit has caused queuing and displacement, as each year, members of older cohorts fill up some of the current dual VET positions (Stalder and Nägele [2011], Gonon and Deissinger [2016], Hoeckel and Schwartz [2010], Baethge and Wolter [2015] $)^{2}$.

\footnotetext{
${ }^{1}$ Both terms refer to the same concept, although 'dual VET' is more often associated with Germany than 'apprenticeship', which is still commonly used in Switzerland or in Austria (Lassnigg 2015).

${ }^{2}$ Although over the last couple of years the number of dual VET positions has substantially increased in Switzerland, fluctuations and displacement still exist; for example, in 2015 around 13 '500 youngsters from the preceding cohorts are still looking for a dual
} 
The impact of business cycles, although relatively small in comparison with other factors, has been empirically established by several studies (Muehlemann et al. [2009], Dietrich and Gerner [2007]). In times of low business activity, the number of dual VET positions decreases.

In addition to these supply side factors, youngsters' aspirations do not always match the requirements of training firms, leading to domain specific imbalances between demand and supply. For example, in 2015 the Swiss barometer of dual VET positions (SERI 2015a) indicates that $16 \%$ of dual VET positions remained vacant in the processing industry, while this rate amounted to only $3 \%$ in sectors such as administration and information (which includes commercial VET) or health and social care.

Unsuccessful dual VET candidates may then opt for another type of education. Within vocational education and training, the other choice is to enroll in school-based VET. School-based VET refers to programs solely taught at the vocational school and which contain limited work-based experience, through internships for example (see, for example, Stalder and Naegele 2011). Admission to these programs is dependent on school specific regulations, in which firms play no part.

Concerning Switzerland, figure 1 presents a two decade long time series on the entrants to VET by mode (all occupations included). This descriptive evidence suggests a certain degree of substitutability between these two modes, as from 1995 and onwards, school-based VET can be seen to move in an anti-cyclical fashion compared to dual VET.

Insert Figure 1 around here

VET contract (SERI 2015a). 
This empirical relationship between the two VET modes also suggests that some students may revise their constrained choice: when the opportunity of a dual VET position arises, they may consider switching VET modes. This type of transition then challenges the horizontal permeability of the VET system. Horizontal permeability is to be understood as the possibility offered to students to smoothly move across types of education within a given level of education, as opposed to vertical permeability which denotes bridges across types of education and between levels (e.g., between upper secondary and tertiary education).

Horizontal permeability has recently emerged as an important topic. In Germany for example, the insufficient permeability of the dual VET system has been recognised as one of the main structural weaknesses of the VET system. The recently launched DECVET initiative intends to tackle this issue setting in place an ambitious system of credit transfer across VET modes, as well as across occupations (Bergzog et al. 2010).

With respect to Switzerland, the importance of both horizontal and vertical permeability is formally recognised in article 9 of the Federal law on VET (2015). Moreover, article 9 alinea 1 explicitly states that the various ordinances should 'guarantee the highest possible level of permeability within vocational education and training'. In practice, the VET system has always been considered as more permeable than its German counterpart, due to a better integration of school-based VET, probably because of its importance in non German speaking parts of the country (SERI 2014). However, at the moment, while the notion of permeability is encouraged, no encompassing system has been designed to implement it across all domains of vocational education and training, such as the German credit system.

Nevertheless, in comparison to a purely academic system, achieving a good 
permeability within a VET system is challenging for several reasons. First, vocational education and training is a domain where emphasis has usually been put on courses and curricula rather than on 'portable competences', i.e., either general or occupation specific human capital (Deissinger [2013], Bergzog et al. [2010]). In Switzerland, this latter aspect has been recognized early on and adressed over the years through several reforms. An important one was the introduction of the Federal vocational matura in 1994, which aimed at increasing the level of general human capital of VET qualification holders (Deissinger and Gonon 2016).

Second, the definition and recognition of those competences directly involves many stakeholders, especially in dual VET systems, such as craft and business associations, the latter being seen as rather 'structurally conservative' (Deissinger et al. 2011) and reluctant to accept changes perceived as eroding the dominance of their training prerogatives.

Given this institutional context, looking at transitions within vocational education and training appears relevant and rather few empirical studies exist on the topic. A relative exception to this rule is the study conducted by Hupka and Stalder (2011) who looked at the differential impact of students' characteristics on their transitions to school-based education vis-à-vis company based training, using a representative Swiss dataset. Although a closely related topic, they did not consider transitions within vocational education and training. To the best of my knowledge, this is the first study looking at such a topic in a quantitative manner.

In the remainder of this paper, the analysis will be focused on commercial VET, the largest VET domain in Switzerland; the next section justifies this choice and discusses several relevant features of this domain. Within the context of Swiss VET, section 3 reviews the reasons why transitions across 
VET modes may occur. For the empirical part, to assess the permeability of the VET system in the commercial domain, the analysis will be focused on a single cohort in the canton of Geneva. The data, the variables and the methodology used are all detailed in section 4 . Section 5 displays and discusses the empirical findings, and the last section concludes.

\section{Commercial VET in Switzerland}

This paper only considers transitions within a given occupation: commercial VET. A number of reasons motivate this choice.

First, commercial VET is an important domain in several countries. In Switzerland, it is actually the largest domain with around $19 \%$ of all VET qualifications awarded each year (Forster-Heinzer et al. 2016). Moreover, commercial vocational education and training is unified under a single occupation called 'Kaufmann/Employé de commerce'. There is thus a correspondingly unique Federal VET certification ('Kaufmann') for all the fields that actually employ commercial dual VET students and professionals, such as, for example, retail companies, public administrations, banks or insurance companies (Pilz 2007). This structure implies that field specific skills are left to the on-the-job training component of the curriculum, while classroom learning is thus (nearly) identical for all commercial dual VET students, irrespectively of their company background ${ }^{3}$.

Second, this field stands out as a relatively large share of students qualify through school-based VET. Even though school-based commercial VET is

\footnotetext{
${ }^{3}$ There are 21 fields of specialisation that VET students can choose from, depending on the firm in which they do their training, but the core school-based curriculum remains common to all trades.
} 
more prevalent in non German speaking regions (SERI 2014) ${ }^{4}$, it is also well developed in the German speaking area, making it a relatively comparable occupational field across Swiss regions. Figure 2 shows the proportions of school-based and dual students by Canton in Switzerland for the year 2012. Although the Canton of Geneva stands on the far right-hand side of the figure, a good number of Swiss Cantons have at least $20 \%$ of school-based students. This highlights that, in commercial VET, the two modes are significant in most Cantons, making an examination of horizontal permeability in this occupation meaningful. Moreover, as horizontal permeability refers to changes across modes of VET, it is independent of the specific proportions of students in each mode.

Insert Figure 2 around here

Third, given its importance, commercial VET has undergone major reforms over the last ten years to modernize both structure and content: 'The rapid changes in the world of industry and business (...) required an adaptation of vocational education in order to match the needs of young people and employers' (Pilz 2007, 70). For instance, one important evolution concerning the content of the school-based curriculum was the introduction of the so-called practice firms, as a means to 'promote the employability of young people by developing skills in a more realistic learning environment' (Deissinger 2006, 191). Practice firms are fictitious firms comprising all usual company departments and are supposed to replicate the on-the-job learning component of the dual curriculum and to bring students more occupational competences. For

\footnotetext{
${ }^{4}$ School-based VET has a more deeply rooted tradition in French-speaking Switzerland, as exemplified in the comparative historical analysis done by Berner, Gonon and Imdorf (2016), which reviews the development of vocational education and training in Geneva and in the Canton of Lucerne.
} 
example, the German Land of Baden-Württemberg introduced practice firms in vocational colleges on a large scale and the end of the 2000s (Deissinger 2007) but this was done only very recently (2011) in the Canton of Geneva ${ }^{5}$, the case study for the empirical analysis.

Finally, note that the Federal law on VET and the corresponding ordinances concern both dual and school-based VET, implying a national harmonization of both curricula with a common core set of classes. However, depending on the Canton, school-based students may additionally follow a set of more general classes, as is foreseen in the Federal ordinance (Commercial VET ordinance, SERI 2015b).

\section{Factors influencing moves across VET modes}

This section intends to lay out the relevant attributes of school-based and dual vocational education and training in Geneva, Switzerland that could, first, motivate the choice between those two routes and, more importantly, generate moves across them. In addition, some of these factors might also be relevant for other Swiss Cantons, as the legal structure of VET is common to all and that school-based commercial VET is important in several Cantons.

As an important preliminary note, neither the type of qualification nor the (theoretical) duration of studies are factors that could differentiate dual VET from school-based vocational education, as they are identical and defined at the Federal level (this does not mean that students may not take longer to attain the qualification, as they may have to repeat a year). Also worth mentioning, no tuition fees are charged for either of those routes, as public

\footnotetext{
${ }^{5}$ Information available on the website of the Department of Education.
} 
upper secondary education is entirely free in Geneva, as is the case in other Cantons.

Concerning differentiating factors and as mentioned in the introduction, a first major difference between school-based and dual vocational education and training is access to each of those two routes. As dual VET is primarily a market driven mode of education, access relies entirely in the hands of firms. Once taken on board by a firm, an apprentice is automatically admitted to the corresponding vocational school, irrespectively of middle school grades and track. For school-based VET students, access is precisely (and solely) conditioned on the latter two variables and, provided that they meet those formal admission requirements, students are automatically admitted (there is no additional restriction of access, as is the case in certain Cantons with upper secondary academic education, see Ryan et al. 2013).

This first major difference implies that access to school-based vocational education and training is probably easier and more direct for most students, as there are no search costs associated with a transition from the lower secondary level to school-based vocational education and training. Consider the following case: a student intends to start a dual VET qualification in an apprenticeship after middle school but is not able to find one (because, for example, of the scarcity of positions in a given sector); he or she thus risks delaying entry in upper secondary education. To avoid such a state, he or she may then directly transition to school-based VET instead, while continuing to look for a dual VET position. Once offered such an opportunity, he or she will change VET modes. In an occupation in which both routes lead to the same qualification, this differential mode of access is thus enough to generate 
moves across VET modes ${ }^{6}$.

As mentioned in the introduction, scarcity in the commercial sector exists at the country level, a situation unchanged since 2005 with an average vacancy rate of about $2 \%$. However, only anecdotal evidence is available on the scarcity of dual VET positions in the commercial sector in Geneva (the Swiss barometer does not contain any occupation specific data at the Cantonal level). Nevertheless, as the proportion of dual VET students (around 0.3 ) is small compared to their school-based counterparts, assuming some scarcity does not appear too strong of an assumption. Moreover, the Cantonal office for training confirmed that, from 2003 to 2006, the number of dual VET positions in the commercial sector decreased significantly in Geneva ${ }^{7}$, supporting the rationing hypothesis.

Second, setting aside the issue of access, the choice between the two modes of VET may also depend on students' preferences over learning methods: some may prefer more contextualized learning, as is more frequent when learning on the job in a dual VET context (Ryan 1998), to more abstract forms of learning that would dominate the curriculum taught in vocational schools. Moreover, students may not always be aware of their preferences over the two learning methods from the start, as compulsory schooling is only based on abstract learning; so that, assuming they transition directly to school-based vocational education and training, time spent at the vocational school may serve as a revealing period to students. Those who find that contextualized

\footnotetext{
${ }^{6}$ School-based vocational education and training at a vocational school is, however, not possible in all occupations and for certain trades (e.g., painters, cooks) only dual VET may lead to a Federal VET certificate (OFPC 2011).

${ }^{7}$ Only the number of concluded contracts is recorded but the latter decreased by around a quarter between 2002 and 2003, a very impressive drop that the Cantonal office purely attributes to a rationing of dual VET positions during those years.
} 
learning suit them best, may then start looking for an opportunity in dual VET and switch modes when the opportunity arises.

Third, incomplete information on differential labour market prospects may also generate moves across modes of VET. As dual VET is spent part time at a firm, employment prospects through internal labour markets are usually better than when qualifying through school-based vocational education and training; Muehlemann and Wolter (2014) indeed find that 33\% of Swiss companies hire nearly all of their dual VET students, once the latter complete training. This rate is however lower (around 25\%) in the French speaking part of the country.

Moreover, even absent any direct retention by the training firm, qualifications obtained through dual VET may be more valued on the labour market and could still generate better employment prospects, as discussed in Ryan (2001). In addition, the recent study done by Hanushek, Woessmann and Zhang (2011) looks at life cycle employment patterns of general vis-à-vis VET graduates and finds that, although VET graduates are more likely to be employed at the beginning of their career, from age 50 and on, general graduates have better chances; a result even more marked for dual VET countries, such as Switzerland. Whether such a result might hold within vocational education and training in some given occupations, comparing the prospects of the two types of qualification holders (school-based or dual VET) is plausible, and especially so given that school-based qualification holders should possess a larger amount of general (and thus more adaptable) skills ${ }^{8}$, but not certain at the moment. Nevertheless, differential and evolving perceptions of

\footnotetext{
${ }^{8}$ In commercial VET, this difference of curriculum indeed exists as school-based VET students additionally follow a set of more general courses (Commercial VET ordinance, SERI 2015b).
} 
employment prospects across modes of VET are enough to generate moves. Fourth, evolving aspirations concerning further education might also motivate students to change VET modes. Although both routes offer identical opportunities on paper, and logically so given that the qualification obtained is identical, in reality, transactions costs might differ. Both dual and schoolbased VET students may prepare the federal vocational Matura and the VET certificate in parallel. However, for dual VET students this latter option involves spending an extra day per week at the vocational school. Given this feature, the SERI Barometer (2015a) reports that around 39\% of firms do not allow their dual VET student to prepare a vocational Matura in parallel because of the extra school time involved. This implies that dual VET students changing their mind about preparing a Matura may either switch to school-based vocational education and training or potentially look for a dual VET position in another firm.

Finally, one last important differential aspect of dual VET is of financial nature. While in training, dual VET students receive a wage, although not a substantial one, whereas school-based VET students earn nothing.Although modest, thisadditionalincome may be used for discretionary spending, a possibly attractive feature to teenagers and in a potentially increasing manner as students get older, motivating moves towards dual VET.

\section{Empirical framework}

\subsection{Data}

In this paper, I use a 10 year panel dataset following the upper secondary pathways of a cohort of 15 year old students in June 2004, i.e., in their last year of middle school, in Geneva, Switzerland. The dataset consists of 
exhaustive administrative data, the Geneva Schooling Database (GSD), on students' characteristics (including 9th grade grades) and school trajectories, which was linked to a subsequent database to include information on qualification (type of qualification obtained and qualification year) for each student. Note that, unfortunately, this database does not contain any information on labour market outcomes.

\subsection{Variables}

Given the focus on the subsample of commercial VET students, table 1 provides the distribution of variables and outcomes of interest across the different subsamples. The reference sample is the complete population cohort; the second subset is made up of individuals having at least a year of education in commercial VET (denoted ' $1+$ ' in the table) and who thus represent the pool of potential commercial VET qualification holders; the third subsample encompasses all individuals who accumulate at least two years in commercial VET (denoted ' $2+$ '), and who are, therefore, capable of moving across modes of VET (who will thus constitute the estimation sample) and, for the sake of completeness, in the last column I report the same set of statistics but only for commercial VET qualification holders. Note that all statistics presented in table 1 are computed after the cohort is observed for the whole period.

Insert Table 1 around here

Looking at the first outcome of interest, the first upper secondary qualification, data show that, as of 2013 , around $78 \%$ of the cohort has obtained an upper secondary qualification. This rate is substantially below the national target rate of $95 \%$ (Swiss Conference of Cantonal Ministers of Education 
2011). Nevertheless, it is possible that in the foreseeable future, some additional students may manage to get a qualification and that some others may, in fact, have qualified abroad, so the true overall rate for this cohort is probably going to be higher. Keeping this caveat in mind, when looking at the variations of the qualification rate across samples, one can note that students accumulating at least two years of commercial vocational education and training are significantly more likely to earn a qualification $(83.18 \%$ ), which is not the case for the ' $1+$ ' sample (76.08\%). Concerning the distribution of qualification holders across VET modes, around $20 \%$ of students qualified through school-based VET. However, the proportion of entirely school based students is quite high among commercial VET qualification holders. For this cohort, $61 \%$ of all VET qualifications obtained through school-based vocation education were delivered in commercial VET.

Concerning changes across VET modes, they are rather seldom when looking at the complete cohort sample and when considering all occupations: only $9 \%$ of individuals ever changed modes. Nevertheless, this rate includes individuals changing occupations as well as VET modes and must therefore be considered with caution. When looking at commercial VET, changes are much more common, with around a quarter of students changing VET modes. Interestingly, changes are even more prevalent among commercial VET qualification holders, suggesting that changes within this occupation are worth examining. Moreover, when examining the pattern of changes across modes in commercial VET, data reveal that for this cohort at least, changes happen almost unidirectionally, from school-based towards dual vocational education and training but note that all types of changes will be accounted for in the empirical analysis. This unidirectional pattern is, however, an interesting feature which would be worth examining further using additional data on 
other cohorts ${ }^{9}$.

With respect to the unadjusted mean time to the first qualification, it does not vary much across samples but this hides substantial variations when one considers the difference between effective and theoretical duration. Commercial VET students (i.e., all students with at least a year spent in commercial VET) take, on average, an extra year and a half to qualify, substantially more than the average extra year for the complete cohort sample. More specifically, table 2 presents the distribution of the number of extra years needed to qualify, the second outcome of interest, for students with at least two years of commercial VET, depending on whether or not they switched modes. This variable corresponds to the difference between the theoretical number of years required for a certain qualification (usually three) and the effective number of years the student spent in upper secondary education before getting this qualification. This variable ranges from minus one for students who finished a year in advance to five extra years. Table 2 illustrates that students who changed VET modes tend to experience a larger delay in qualification than students who did not change.

Finally, to get a sense of the achievement level across subsamples, the last part of table 1 present the breakdown of students depending on their last school track and 9th grade GPA quartile. Interestingly, although the distribution of students across middle school tracks is not dramatically different from the whole cohort, the group of commercial VET students seems to be biased towards middle achievers, with the best students strongly underrep-

\footnotetext{
${ }^{9}$ Note that this unidirectionality of changes is consistent with the fact that the regular compulsory school curriculum only uses abstract learning and that students must wait until upper secondary education to get acquainted with contextualized learning, although, of course, in smaller proportions in the school-based compared to the dual VET mode.
} 
resented in all commercial VET samples. For more information, appendix table A.1 provides the distribution of a few other individual characteristics across subsamples.

\section{Insert Table 2 around here}

Appendix table A.2 presents a few additional summary statistics for the individual-year specific probability to qualify on the estimation sample, i.e., all students totaling at least two years of commercial VET. This variable is defined up until the first upper secondary qualification when it takes the value one. The number of years observed for each student therefore varies, from a minimum of three years to a maximum of ten, with most individuals observed for either 6 or 7 periods (average is 6.6$)^{10}$.

To conclude this section, table 3 lists the proportions of a few covariates for individuals who did and did not change VET modes (the estimation sample), on the subsample of individuals with at least two years spent in commercial VET. Most variables are in a similar proportion across both subsamples but noticeably girls seem to change modes less often than boys, as are the highest performing students and individuals with a high socioeconomic status (managerial background).

Insert Table 3 around here

\subsection{Empirical strategy}

To credibly estimate the effect of changes across VET modes on the upper secondary qualification probability, one needs to take into account unobservable heterogeneity, which will be denoted by $c_{i}$. For example, given that

\footnotetext{
${ }^{10}$ Table A.2 also highlights that most of the variation concerning this variable occurs within individuals over time, as opposed to across individuals (the between component).
} 
changes across modes are essentially moves towards dual VET and given a potential scarcity of dual VET positions, unobserved professional or family networks might prove useful when finding an dual VET contract. This argument implies that only resource-possessing individuals would experience a switch across VET modes and that such individuals are also more likely to qualify and to do so on time. In a linear (OLS) setting, this could be easily dealt with using fixed effects, the latter allowing any kind of dependence between unobserved time invariant heterogeneity and the covariates. In the non linear case, treating fixed effects as parameters to estimate produces inconsistent results, the so-called incidental parameter problem (Wooldridge 2010). The usual approach is thus to specify a certain form of dependence between unobserved heterogeneity and the covariates $\mathbf{x}_{i t}$. Consider the following unobserved effect model for the qualification probability of individual $i$ at time $t$ :

$$
P\left(y_{i t}=1 \mid \mathbf{x}_{i t}, c_{i}\right)=\Phi\left(\mathbf{x}_{i t}^{\prime} \boldsymbol{\beta}+c_{i}\right)
$$

where $y_{i t}$ denotes qualification, $\Phi($.$) is the normal cumulative distribution$ function (cdf), $\mathbf{x}_{i t}$ the set of covariates, including time and non time varying variables and $c_{i}$ refers to the unobserved time constant heterogeneity. In this particular setting, there is only one time varying variable, the dummy variable denoting changes across VET modes. To identify the $\beta \mathrm{s}$ and partial or marginal effects (i.e. the impact of a variation in a given covariate on the predicted probability), one needs additional assumptions. However, there is a trade-off, the more assumptions one is willing to make, the more quantities one is able to estimate. Moreover, as these assumptions are needed for consistency, each additional assumption carries an extra weight. The 
traditional random effect probit model (problematically) assumes independence between unobserved heterogeneity and the covariates. This is rather simplistic, as most often unobserved heterogeneity is indeed correlated with the covariates (regressors) and, in this case, the random effect probit model would yield inconsistent estimates.

As an alternative, the correlated random effect (CRE) model, proposed by Mundlak (1978) and by Chamberlain (1980), relies on a more realistic form of dependence between unobserved heterogeneity, $c_{i}$, and the covariates. Specifically, the CRE model postulates that the dependence between unobserved heterogeneity and the covariates is only (linearly) channeled through the mean of $c_{i}$ and takes the following form:

$$
c_{i} \mid \mathbf{x}_{i} \sim N\left(\psi+\overline{\mathbf{x}}_{i}^{\prime} \boldsymbol{\xi}, \sigma_{a}^{2}\right)
$$

where $\overline{\mathbf{x}}_{i}$ is the average of $\mathbf{x}_{i t}$ over all periods, $\psi$ is a parameter, $\sigma_{a}^{2}$ the the unknown variance of $c_{i}$ and $N$ denotes the normal distribution. As one can see from equation 2 , the conditional mean of $c_{i}$, the unobserved heterogeneity, is thus composed of an unknown parameter $(\psi)$ and of an average of the time varying covariates $\left(\overline{\mathbf{x}}_{i}\right)$. The variance of $c_{i}$ is assumed to be independent from the covariates. Adding two more assumptions ${ }^{11}$, the CRE model identifies both the coefficients and the average partial effects (APEs).

Practically, the CRE is very easily estimated by adding the average of the time varying covariates to the set of existing covariates. Moreover, as the traditional random effect probit model is nested within the more general CRE model, estimating a CRE model permits to test the validity of the

\footnotetext{
${ }^{11}$ Namely, i) the strict exogeneity of the covariates conditional on $c_{i}$, and ii) the independence of responses $\left(y_{i t}\right)$ conditional on unobserved heterogeneity and the covariates.
} 
independence assumption by looking at the significance of the $\xi$ s. If the latter turn out significantly different from zero, then this is evidence against the traditional random effect model. The CRE model is estimated using maximum likelihood techniques and this model will later on be referred to as 'MLE CRE model', where 'MLE' stands for maximum likelihood estimator.

Finally, a less restrictive model is the pooled CRE model, which compared to the previous model, needs only a reduced set of assumptions ${ }^{12}$ and still permits to identify the average partial (or marginal) effects. However, only a scaled vector of coefficient can be estimated (see Wooldridge 2010 for more details). Among the models considered here, the pooled correlated random effect probit model is the least restrictive in terms of model assumptions, while still allowing to estimate the average partial effects (APE) ${ }^{13}$ and is thus an appealing option.

The main advantage of correlated random effect models is that all usual confounding factors when dealing with educational outcomes, such as personality traits (conscientiousness for example), motivation or ability are accounted for in a specific sense: they are allowed to be correlated with the regressors, provided that they are time invariant. It has been shown that they can indeed be considered fixed over the sort of period considered here (see Almlund et al. 2011). The main limitation is, of course, the restricted nature of the relationship between $c_{i}$ and the covariates.

In sum, this kind of model credibly deals with unobserved heterogeneity and provides estimates that are thought to be closer to causal effects than to

\footnotetext{
${ }^{12}$ Assumption (ii) is relaxed.

${ }^{13}$ When dealing with unobserved heterogeneity and in certain models, as is the case with CRE models, partial effects averaged across the sample, i.e. APE, can be shown not to depend on $c_{i}$ and can thus be computed (see Wooldridge 2010 for more details).
} 
correlations. Finally, note that the effect on the probability to qualify is identified thanks to movers, i.e. students who switch VET modes, in the subsample of students who are capable of moving across mode, i.e., those with at least two years of commercial VET.

In a second time, to get a sense of the impact of changing VET modes on the time needed to qualify, I estimate a simple sample selection model à la Heckman (1979). This procedure is justified since the effective number of years spent in upper secondary education before qualifying is only observed for students who do qualify and that the qualification variable cannot be considered to be missing at random, i.e., error terms across both equations are correlated. If the errors are assumed to be jointly normally distributed, one can specify the complete log likelihood function to estimate and, provided that the distributional assumptions are not violated, such a strategy produces efficient estimators (Amemiya 1985). This model will be referred to as a maximum likelihood (MLE) model. Theoretically, this type of model can be identified only through distributional assumptions.

The Heckman two step procedure relies on weaker distributional assumptions $^{14}$ and is therefore expected to be more robust (Cameron and Trivedi 2005). In addition, it is computationally very easy: the selection bias is dealt with estimating selection stage inverse Mills ratios and adding them subsequently to the second stage outcome equation. In this case, the credibility of the two step procedure relies on the availability of exclusion restrictions, otherwise the parameters of interest are identified only through the non linearity of the inverse Mills ratios which is quite problematic (for a review on this issue, see Puhani 2000).

\footnotetext{
${ }^{14}$ Specifically, the univariate normality of the error term in the outcome equation and a linear dependence between the error terms across equations.
} 


\section{Results}

I now present estimates resulting from all models specified in the previous section, so as to compare the impact of the various assumptions on the estimated quantities (parameters and/or partial effects). Close results between models would indicate a certain degree of robustness, in the sense that the effect does not depend on a single set of assumptions but holds across a whole range.

Table 4 displays the first set of estimations, where the variable of interest, denoting changes across VET modes (irrespectively of their direction), is positive and significant across all specifications, suggesting a positive impact of these transitions on the probability to qualify.

The first column displays the simple OLS results that are, as expected, downward biased compared to all other estimators taking unobserved heterogeneity into account. The linear fixed effect model presented in column 2 suggests that changing VET modes increases the qualification probability by about 19 percentage points, which is about twice the size of the simple OLS coefficient (and corresponds to the within effect of changing modes). However, remember that in the binary case, fixed effect estimation produces inconsistent estimates, so that this specification cannot be the preferred one.

Column 3 displays estimates from a simple random effect (pooled) probit model, which, as discussed, assumes that unobserved heterogeneity is independent of the covariates. The average partial (or marginal) effect indicates an increase of 11 percentage points induced by a change of modes. Moreover, this model is strongly rejected by the data as in both CRE models (columns 5 and 7 ) the time average 'changed modes' variable appears significant, suggesting that unobserved heterogeneity is indeed correlated with the 
regressors.

Columns 5 and 7 present the estimated parameters of correlated and pooled correlated random effect models respectively, while the immediately adjacent columns, 6 and 8, report the corresponding average partial effects (APE). Both average partial effects are indeed higher than in all other models, with a 36 percentage point increase in the qualification probability induced by a switch across VET modes. Such close APEs across both models suggest that the additional assumption ${ }^{15}$ necessary for the simple correlated random effect probit (denoted MLE CRE probit in the table) does not seem too problematic.

With respect to the magnitude of the APEs, 36 percentage points represents a large impact, especially taking into account the fact that (time invariant) unobserved heterogeneity, such as family networks, motivation or ability, has been accounted for (in the sense that the latter are allowed to be correlated with the regressors). This result can therefore reflect the strong attraction and retention potential of dual VET as a powerful medium of upper secondary qualification. However, the story does not end here. Even if a transition from school-based VET appears as a positive event in increasing apprentices' qualification probability, one important drawback can be the potential cost associated with delayed qualification.

Insert Table 4 around here

In a perfectly permeable system, going from full-time to dual VET within a given occupation should a priori not increase the number of years necessary to qualify. However, results presented in table 5 suggest that changing VET

\footnotetext{
${ }^{15}$ Namely the independence of responses.
} 
modes is indeed associated with an increase in the qualification delay of around half a year, as supported by all specifications and assuming that the training efficacy of both VET modes is identical (which is supported by a common qualification and study duration).

Column 1 presents the simple OLS results on the selected sample. The estimated parameter of 0.54 , representing a delay of around half a year, thus has to be interpreted as the lower bound estimate of the true effect of changing modes. This result implies that transitions across VET modes can reasonably be considered to delay certification.

Columns 2 to 4 present results obtained from sample selection models. Note that the maximum likelihood method presented in column 2 does not formally require any exclusion restriction for identification, but the small sample size makes this kind of strategy very fragile. Models estimated in columns 3 and 4 both use exclusion restrictions. However, one important caveat is, as always, the difficulty of finding a credible exclusion restriction. In both cases, socio-economic status, gender and whether or not the individual lives with both parents are used as exclusion restrictions. The idea is that such characteristics are likely to affect the probability of getting a qualification, but not the speed. The speed is assumed to depend only on the individual's ability, as captured by the GPA quartile. The estimated effect of changing modes using the two part model (column 4 ) is only significant at the 5 percent level, which is expected given that standard errors now account for the first stage estimation of the inverse Mills ratios $^{16}$.

Finally, out of three sample selection models, only the MLE with exclusion re-

\footnotetext{
${ }^{16}$ Because standard errors at the second stage have to account that one of the variables, namely the inverse Mills ratio, is not an observed variable but is already an estimated quantity (see Cameron and Trivedi 2005 for more explanations).
} 
strictions (column 3) produces evidence of sample selection, as the estimated coefficient on the inverse Mills ratio is significant (denoted $\hat{\lambda}$ in the table). This inconclusive evidence of sample selection explains why OLS results are so close to the three sample selection models considered.

In sum, even if results from sample selection models might appear debatable because of both the small sample size and the precariousness of the exclusion restrictions, one can always rely on the simple OLS coefficient. Assuming that individuals who change VET modes positively self select themselves (which is indeed very likely), we still learn that those changes imply a delay which amounts, at the very least, to around half a year.

Concerning GPA quartiles, comparing the relative magnitude of the fourth and third GPA quartile coefficients to the changed modes dummy, one implication is that only high achievers (fourth quartile) may, in the end, compensate this time cost. Note that, as permeability across VET modes is not formally recognised, when a student changes VET modes, his situation is assessed on a case by case basis ${ }^{17}$, implying that the level of achievement will most likely be factored in when deciding which classes the student must resit. Finally, with the data at hand, one cannot disentangle the precise reasons behind this delay. It remains some sort of a black box that only qualitative analysis could open.

Insert Table 5 around here

To summarise the empirical findings, there is substantial supportive evidence that even though movers need more years to qualify, they are still more likely

\footnotetext{
${ }^{17}$ The lack of formal rules and this ad hoc procedure was indeed confirmed through interviews with experienced actors in the field.
} 
to get an upper secondary qualification. There is, therefore, a strong evidence that, even though, changing VET modes increases the time to qualification, it does not hamper student's qualification prospects.

\section{Conclusion}

This paper examined the horizontal permeability of the Swiss VET system, i.e., the impact of transitions across VET modes. Formally recognised as important by the Swiss law on VET, horizontal permeability has emerged as a new challenge for VET systems. Using longitudinal data for a cohort in the Canton of Geneva, the empirical analysis looked at the impact of a within occupation transition across VET modes on the qualification success of commercial VET students. Commercial VET is the largest field of vocational education and training at both the country and Cantonal levels and has the largest share of exclusively school-based students. Allowing unobserved heterogeneity to be correlated with the regressors, I find that changing VET modes, which essentially means transitioning from school-based to dual vocational education and training, increases students' qualification probability by a large magnitude (around 36 percentage points). Due to a lack of permeability between modes of education, this type of transition is however associated with an extended delay towards qualification (amounting to around half a year). Given the Federal structure of VET, this lack of permeability in commercial VET is likely to exist elsewhere in Switzerland, although to a varying degree, as the implementation of ordinances may vary from one Canton to the next. By contrast, the validity of these findings for other occupations remains uncertain. Another clear limitation is the sample size; extending the analysis to other cohorts would provide a good robustness check. 
Even though this transfer approach appears broadly desirable from a public policy perspective, the question remains as to whether or not firms might be willing to sponsor such a permeable training scheme, a crucial point given their importance within dual vocational education and training. If transitions are mostly going from school-based to dual VET, then firms would obviously gain from a more permeable system: their newly recruited apprentice could easily transfer all the school-based competences already acquired and complement it with the on-the-job training part of the curriculum. This is a clear win-win situation for all parties involved. If, however, some transitions were to go freely from dual to school-based vocational education and training, within a given occupation, some firms might incur a cost as their initial investment in the apprentice might not be recouped, especially so if the move intervenes after the first year, the most training intensive and costly one for the firm (Wolter and Ryan 2011).

The permeability of the Swiss VET system has often been highlighted as one of the key factors of its success (OECD 2009); however, this flexibility mainly takes into account transitions across types of education, for example between academic and vocational education and training, and mostly at the interface of major educational cycles, i.e., between lower and upper secondary and between upper secondary and tertiary levels. So far, probably due to the dominance of dual VET, transitions within VET have been relatively neglected. Nevertheless, the future development of vocational education and training is very likely to call for a reflection along those lines. A more comprehensive implementation of article 9 of the Swiss Federal law on VET will only be possible once both types of permeability are each fully taken into account. Following Germany, re-evaluating the complete framework of assessment currently used could be one possible pathway. Whichever solution 
Switzerland may choose will have to balance the interests of all stakeholders involved: firms, students, and public authorities. 
Almlund, M., A. L. Duckworth, J. Heckman, and T. Kautz (2011). Personality Psychology and Economics. In S. M. a. L. W. Eric A. Hanushek (Ed.), Handbook of the Economics of Education, Volume Volume 4 of Handbook of The Economics of Education, pp. 1-181. Elsevier.

Amemiya, T. (1985). Advanced econometrics. Cambridge (MA): Harvard university press.

Baethge, M. and A. Wolter (2015). The German skill formation model in transition: from dual system of VET to higher education? Journal for Labour Market Research 48(2), 97-112.

Bergzog, T., A. Diettrich, C. Koehlmann-Eckel, and E. Meerten (2010). The DECVET pilot initiative crediting competences- improving permeability. Technical report, Federal Ministry of Education and Research (BMBF), Bonn, Berlin.

Berner, E., P. Gonon, and C. Imdorf (2016). The genesis of vocational education in Switzerland from the perspective of justification theory: On the development of a dual vocational education model in the Cantons of Geneva and Lucerne In press. In E. Berner and P. Gonon (Eds.), Vocational Education and Training in Europe: Cases, Concepts and Challenges. Bern: Peter Lang.

Busemeyer, M. R. and C. Trampusch (Eds.) (2011). The Political Economy of Collective Skill Formation. Oxford: Oxford University Press.

Cameron, A. and P. Trivedi (2005). Microeconometrics methods and applications. Cambridge; New York: Cambridge University Press.

Chamberlain, G. (1980). Analysis of covariance with qualitative data. Review of economic studies 47, 225-238.

Culpepper, P. D. and K. Thelen (2008). Institutions and Collective Actors in the Provision of Training: Historical and Cross-National Comparisons. In K. U. Mayer and S. Heike (Eds.), Skill Formation: Interdisciplinary and Cross-National Perspectives, pp. 87-116. Cambridge (UK): Cambridge University Press.

Deissinger, T. (2006). The apprenticeship crisis in Germany: the national debate and implication for full-time vocational education and training. In L. Mjelde and R. Daly (Eds.), Working knowledge in a globalizing world: from work to learning, from learning to work, Volume 3 of Studien zur 
Berufs- und Weiterbildung, Studies in vocational and continuing education, pp. 181-196. Bern : New York: P. Lang.

Deissinger, T. (2007). "Making schools practical": Practice firms and their function in the full-time vocational school system in Germany. Education + Training 49(5), 364-379.

Deissinger, T. (2013). Is the German Qualifications Framework an Instrument that Contributes to Permeability and Progression Within the VET System? - An International Perspective. In From Diagnostics to Learning Success, Number 1 in Professional and VET learning, pp. 295-307. SensePublishers.

Deissinger, T. and P. Gonon (2016). Stakeholders in the German and Swiss vocational educational and training system: Their role in innovating apprenticeships against the background of academisation. Education + Training 58(6), 568-577.

Deissinger, T., R. Heine, and M. Ott (2011). The dominance of apprenticeships in the German VET system and its implications for Europeanisation: a comparative view in the context of the EQF and the European LLL strategy. Journal of Vocational Education \& Training 63(3), 397-416.

Dietrich, H. and H. D. Gerner (2007). The determinants of apprenticeship training with particular reference to business expectations. Zeitschrift für ArbeitsmarktForschung; Journal for Labour Market Research 40 (2-3), 221233.

EDK (2011). Projet transition: rapport final. Technical report, Swiss Conference of Cantonal Ministers of Education (EDK), Bern.

Forster-Heinzer, S., D. Holtsch, S. Rohr-Mentele, and F. Eberle (2016). Do they intend to stay? An empirical study of commercial apprentices' motivation, satisfaction and intention to remain within the learned occupation. Empirical Research in Vocational Education and Training 8(1), 16.

Hanushek, E. A., L. Woessmann, and L. Zhang (2011). General education, vocational education, and labor-market outcomes over the life-cycle. Technical Report Discussion Paper No. 6083, IZA Institute for the Study of Labor, Bonn.

Heckman, J. J. (1979). Sample selection bias as a specification error. Econometrica: Journal of the econometric society, 153-161. 
Hoeckel, K. and R. Schwartz (2010). Learning for Jobs: OECD Reviews of Vocational Education and Training: Germany. Paris: Organisation for Economic Co-operation and Development.

Hupka, S. and B. E. Stalder (2011). Jeunes migrantes et migrants à la charnière du secondaire I et du secondaire II. In Youth transitions in Switzerland: Results from the TREE panel study, Volume 1, pp. 183-200. Zürich: Seismo.

Lassnigg, L. (2015). The Political Branding of Apprenticeship into the 'Dual System': Reflections about Exporting the Myth of Employment Transition. In A. Heikkinen and L. Lassnigg (Eds.), Myths and Brands in Vocational Education, pp. 78-98. Newcastle upon Tyne: Cambridge Scholars Publishing.

Muehlemann, S. and S. C. Wolter (2014). Return on investment of apprenticeship systems for enterprises: Evidence from cost-benefit analyses. IZA Journal of Labor Policy 3(1), 1-22.

Muehlemann, S., S. C. Wolter, and A. Wueest (2009). Apprenticeship training and the business cycle. Empirical research in vocational education and training 1(2), 173-186.

Mundlak, Y. (1978). On the pooling of time series and cross section data. Econometrica: journal of the Econometric Society, 69-85.

OECD (2009). Systemic innovations in the Swiss vocational education and training system- OECD coutry case study report. Technical report, Organization for Economic Cooperation and Development, Paris.

OFPC (2011). Après la scolarité obligatoire (Office pour l'orientation, la formation professionnelle et continue ed.). Geneva, Switzerland: République et Canton de Genève.

Pilz, M. (2007). Two countries-one system of vocational education? a comparison of the apprenticeship reform in the commercial sector in Switzerland and Germany. Compare: A Journal of Comparative and International Education 37(1), 69-87.

Puhani, P. (2000). The Heckman correction for sample selection and its critique. Journal of economic surveys 14(1), 53-68.

Ryan, P. (1998). Is apprenticeship better? a review of the economic evidence. Journal of Vocational Education \&5 Training 50(2), 289-329. 
Ryan, P. (2001). The School-to-Work Transition: A Cross-National Perspective. Journal of Economic Literature 39(1), 34-92.

Ryan, P., U. Backes-Gellner, S. Teuber, and K. Wagner (2013). Apprentice pay in Britain, Germany and Switzerland: Institutions, market forces and market power. European Journal of Industrial Relations 19(3), 201-220.

Schweri, J. and B. Mueller (2007). Why has the share of training firms declined in Switzerland. Zeitschrift für ArbeitsmarktForschung; Journal for Labour Market Research 40(2/3), 149-167.

Stalder, B. E. and C. Naegele (2011). Vocational education and training in Switzerland: Organisation, development and challenges for the future. In Youth transitions in Switzerland: Results from the TREE panel study, Volume 1, pp. 18-39. Zürich: Seismo.

State Secretariat for Education, Research and Innovation (SERI) (2014). La formation professionnelle en Suisse: faits, données et chiffres. Technical report, SERI, Bern.

State Secretariat for Education, Research and Innovation (SERI) (2015a). Baromètre suisse des places d'apprentissage. Technical report, SERI, Bern.

State Secretariat for Education, Research and Innovation (SERI) (2015b). Ordonnance sur la formation professionnelle initiale d'Employé de commerce avec certificat fédéral de capacité (CFC). Bern.

State Secretariat for Education, Research and Innovation (SERI) (2016). La formation professionnelle en Suisse: faits et chiffres 2016. Technical report, SERI, Bern.

Swiss Federal Statistical Office (2014). Employés de commerce CFC ou élève des écoles de commerce par canton et forme d'enseignement 2012. Technical report, Swiss Federal Statistical Office (SFSO), Neuchlâtel.

Swiss Federal Statistical Office (2016). Mode d'enseignement des formations professionnelles initiales, 1990-2014. Technical report, Swiss Federal Statistical Office (SFSO), Neuchlâtel.

Swiss legislative authority (2015). Federal law on vocational education and training. Bern: SERI.

Trampusch, C. (2010). Employers, the State and the politics of institutional change: Vocational education and training in Austria, Germany and Switzerland. European Journal of Political Research 49(4), 545-573. 
Wolter, S. C. and P. Ryan (2011). Apprenticeship. In E. A. Hanushek, S. Machin, and L. Woessmann (Eds.), Handbook of the Economics of Education, Volume 3, pp. 521-576. Elsevier.

Wooldridge, J. M. (2010). Econometric analysis of cross section and panel data (2nd ed ed.). Cambridge, Mass: MIT Press. 
Table 1: Selected descriptive statistics by subsample

\begin{tabular}{|c|c|c|c|c|c|}
\hline \multirow{3}{*}{ Variable refers to } & \multirow[b]{3}{*}{$N$} & \multirow[t]{2}{*}{$\begin{array}{c}\text { Full } \\
\text { Cohort }\end{array}$} & \multicolumn{3}{|c|}{$\begin{array}{l}\text { CVET } \\
\text { students }\end{array}$} \\
\hline & & & $1+$ & $2+$ & have qualified \\
\hline & & 3,324 & 857 & 672 & 442 \\
\hline Upper secondary qualification & ever obtained a qualification & 78.22 & 76.08 & 83.18 & 100.00 \\
\hline \multirow{5}{*}{ Type of upp. sec. qualification } & school-based VET qualification & 18.88 & 47.09 & 54.03 & 68.03 \\
\hline & of which in CVET & 61.10 & 97.72 & 99.34 & 100.00 \\
\hline & dual VET qualification & 19.88 & 32.67 & 29.70 & 31.97 \\
\hline & of which in CVET & 27.27 & 66.20 & 84.94 & 100.00 \\
\hline & general qualification & 57.08 & 16.41 & 13.24 & 0.00 \\
\hline \multirow[t]{2}{*}{ VET mode } & ever changed VET mode & 8.97 & 25.90 & 22.02 & 18.33 \\
\hline & if changed, from school-based to dual VET & 94.29 & 97.30 & 95.94 & 96.30 \\
\hline \multirow[t]{2}{*}{ Time to first qualification } & mean time to 1 st qualification (year) & 4.49 & 4.77 & 4.69 & 4.57 \\
\hline & mean n. of extra years to qualification & 1.00 & 1.62 & 1.53 & 1.46 \\
\hline \multirow[t]{3}{*}{ Lower secondary track } & high track & 59.76 & 51.58 & 57.29 & 61.54 \\
\hline & low track & 21.30 & 28.77 & 23.96 & 21.49 \\
\hline & delayed tracking & 18.94 & 19.65 & 18.75 & 16.97 \\
\hline \multirow[t]{4}{*}{ Lower secondary GPA quartile } & lowest achievers & 24.46 & 32.44 & 29.91 & 29.19 \\
\hline & low achievers & 24.43 & 33.37 & 32.59 & 32.58 \\
\hline & high achievers & 24.46 & 24.50 & 26.04 & 27.83 \\
\hline & highest achievers & 26.65 & 9.68 & 11.46 & 10.41 \\
\hline
\end{tabular}

Data source: GSD Administrative data, 2003-2013.

Notes: Numbers represent percentages (when not otherwise specified). 'CVET' stands for commercial vocational

education and training. Qualification types do not sum to 100 , as foreign qualifications are not included in the table.

The category '1+' ('2+') refer to students with at least a (two) year(s) spent in CVET.

Normal duration to qualify is 3 years, but may be 2 or 4 depending on the qualification obtained. 
Table 2: Distribution of the number of extra years needed to qualify for the subsample of students with at least two years of commercial VET, for those who did and did not change modes of VET

\begin{tabular}{lcccc}
\hline & N. of years & \multicolumn{2}{c}{ N. of ids } & Total \\
\hline & & stayers & changers \\
\hline Finished early & -1 & 13 & 0 & 13 \\
On time & 0 & 133 & 6 & 139 \\
Finished with a delay of & 1 & 147 & 21 & 168 \\
& 2 & 89 & 21 & 110 \\
& 3 & 33 & 28 & 61 \\
& 4 & 21 & 22 & 43 \\
& 5 & 10 & 15 & 25 \\
\hline Total & & 446 & 113 & 559 \\
\hline
\end{tabular}

Data source: GSD Administrative data, 2003-2013.

Notes: 'Changers' refers to individuals who changed modes of VET.

As of 2013, 113 individuals haven't qualified yet. 
Table 3: Distribution of selected covariates for individuals who did and did not change VET modes (in percent)

\begin{tabular}{llll}
\hline & & Stayers & Changers \\
\hline Lower secondary track & N & 524 & 148 \\
& High track & 59.73 & 48.65 \\
& Dow track & 21.95 & 31.08 \\
Lower secondary GPA quartile & Lowest achievers & 18.32 & 20.27 \\
& Low achievers & 31.87 & 33.11 \\
& High achievers & 25.95 & 26.35 \\
Gender & Highest achievers & 13.17 & 5.41 \\
Family structure & Girl & 50.57 & 37.16 \\
Language spoken at home & Lives with both parents & 70.42 & 63.51 \\
Nationality groups & Non French-speaker & 45.61 & 46.62 \\
& Switzerland & 62.02 & 58.78 \\
& Spain and Italy & 10.69 & 8.11 \\
& Portugal & 11.26 & 14.86 \\
& Balkans and Turkey & 6.49 & 8.11 \\
& Rest of EU 27 & 2.10 & 0.68 \\
& Rest of the World & 7.44 & 9.46 \\
& White collars & 36.64 & 44.59 \\
& Managerial workers & 10.31 & 3.38 \\
& Self employed & 8.21 & 6.76 \\
& Blue collars & 38.93 & 39.86 \\
& Misc. /NA & 5.92 & 5.41 \\
\hline
\end{tabular}

Data source: GSD Administrative data, 2003-2013.

Note: the total $(\mathrm{N}=672)$ corresponds to the number of students with at least two years in commercial VET. 
Table 5: The impact of changing VET modes on the qualification delay

\begin{tabular}{lcccc}
\hline & & \multicolumn{3}{c}{ Sample selection } \\
\hline & OLS & \multicolumn{1}{c}{ MLE } & MLE & Two steps \\
\hline changed modes & $(1)$ & \multicolumn{1}{c}{$(2)$} & $(3)$ & $(4)$ \\
& $\left(0.5380^{* * *}\right.$ & $0.4843^{* *}$ & $0.6784^{* * *}$ & $0.5477^{* *}$ \\
2nd GPA quartile & -0.0458 & $(0.2161)$ & $(0.2247)$ & $(0.2206)$ \\
& $(0.1648)$ & $(0.1681)$ & $(0.1880)$ & $(0.2065)$ \\
3rd GPA quartile & $-0.4194^{* *}$ & $-0.3697^{* *}$ & 0.0114 & $-0.3740^{*}$ \\
& $(0.1633)$ & $(0.1826)$ & $(0.1872)$ & $(0.2267)$ \\
4th GPA quartile & $-0.9356^{* * *}$ & $-0.8595^{* * *}$ & $-0.4158^{*}$ & $-0.8805^{* * *}$ \\
& $(0.1979)$ & $(0.2274)$ & $(0.2212)$ & $(0.2817)$ \\
$\hat{\lambda}$ & & -0.0571 & $1.6708^{* * *}$ & 0.2287 \\
& & $(0.4464)$ & $(0.0639)$ & $(0.7988)$ \\
\hline $\mathrm{N}$ & 559 & \multicolumn{3}{c}{672} \\
Exclusion restrictions & - & no & yes & yes \\
\hline
\end{tabular}

Legend: * $0.10 * * 0.05 * * * 0.01$

Notes: Dependent variable is the difference between effective and theoretical duration, as presented in table 2. Standard error are reported in parenthesis.

'MLE' stands for maximul likelihood.

For the OLS and MLE models, variance is robust and for the two step estimator, standard errors take into account the first step estimation of $\lambda$, the inverse Mills ratio. Results for the selection equation are omitted.

SES, gender and family structure are used as exclusion restrictions. 


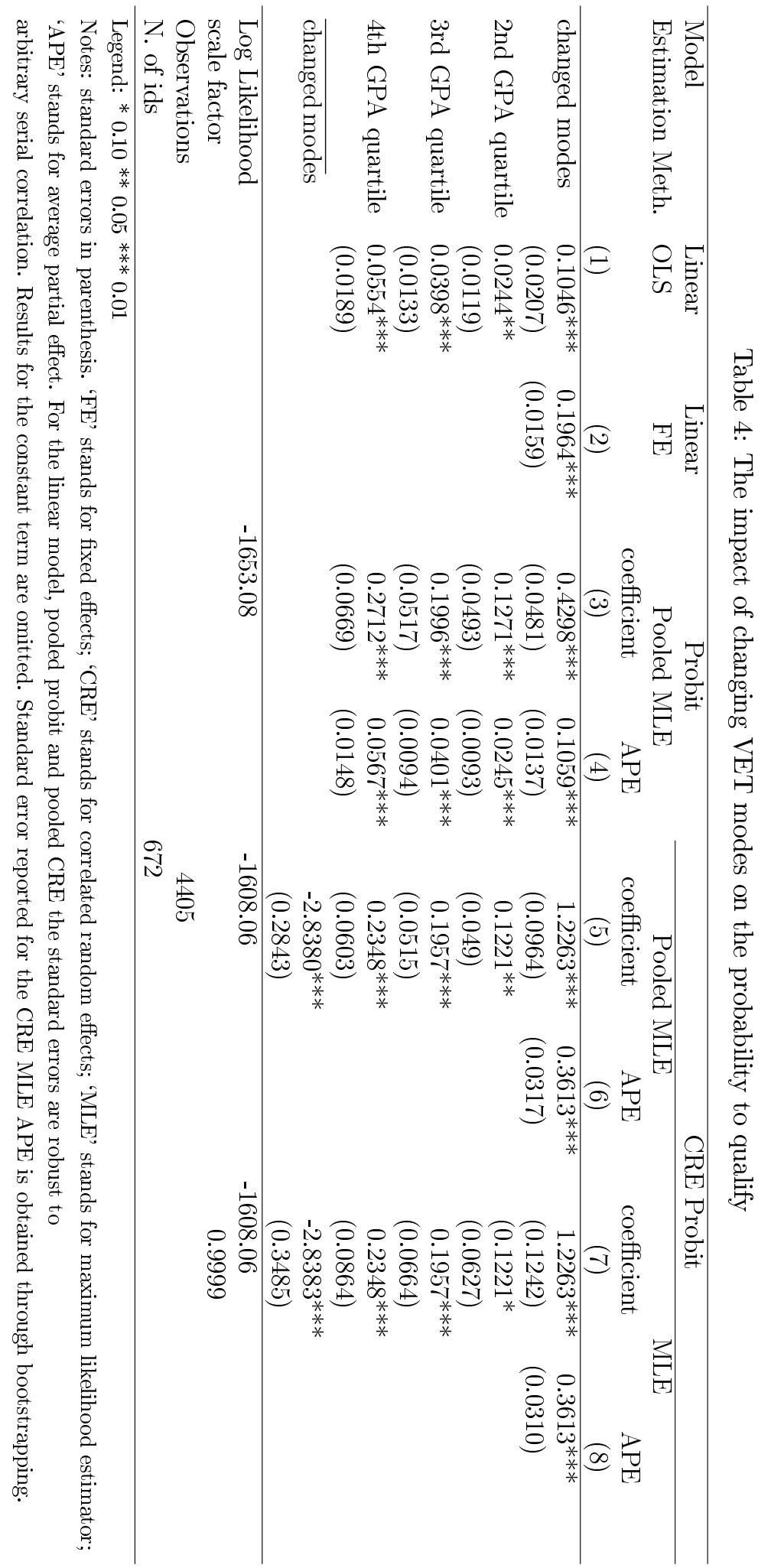


Figure 1: New entrants to initial VET in Switzerland by VET mode

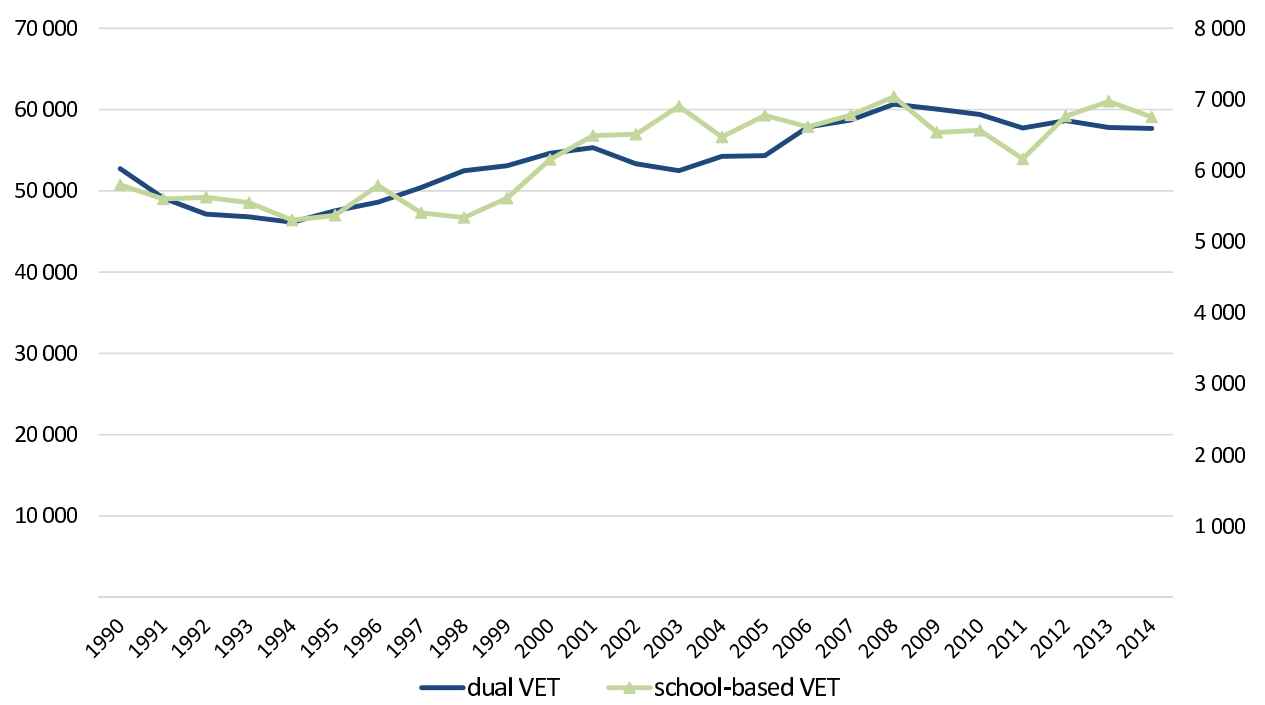

Data source: Swiss Federal Statistical Office (2016).

Note: entrants to school-based VET are displayed on the right axis. 
Figure 2: Shares of school-based and dual VET students in commercial VET by Canton in 2012 (in percent)

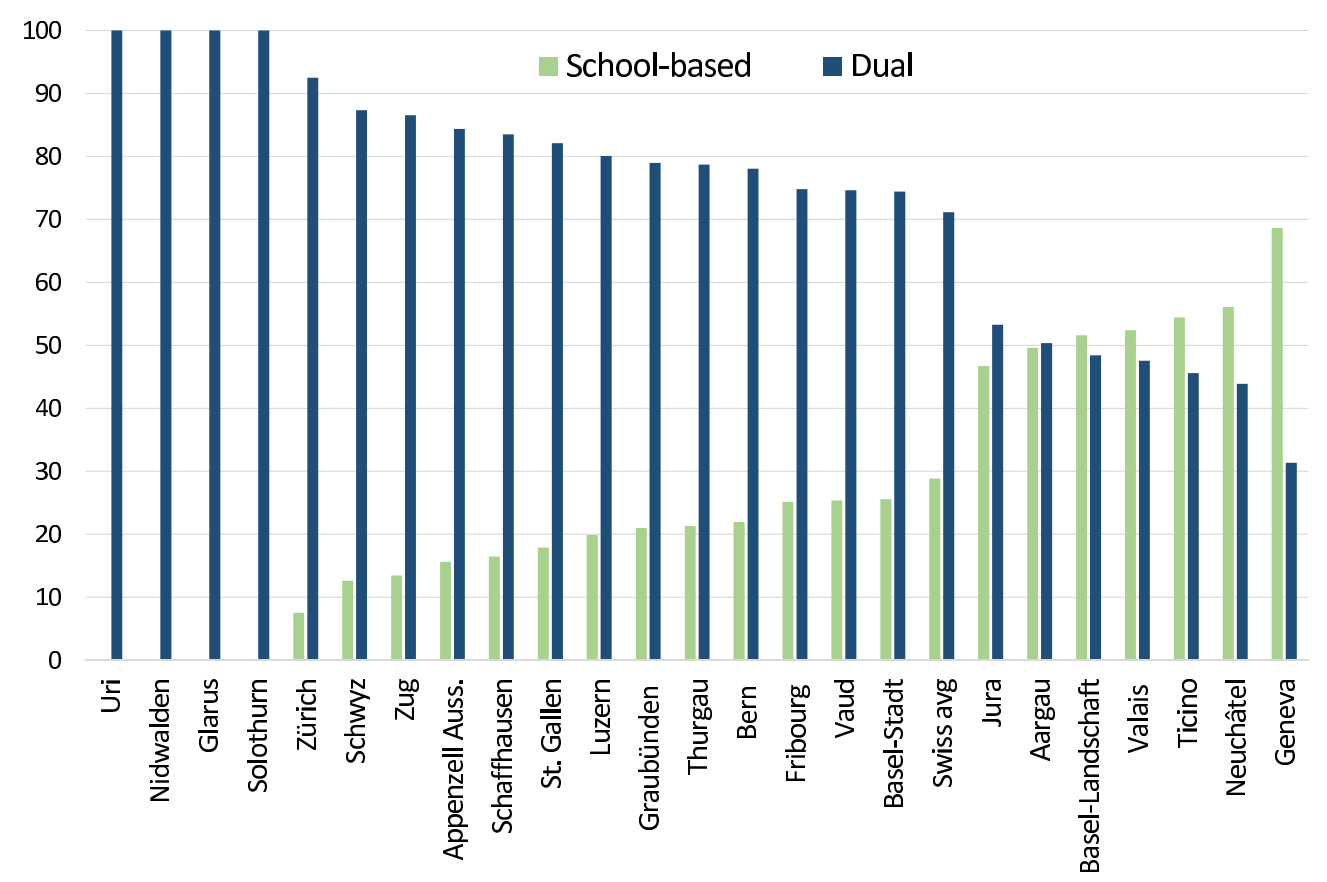

Data source: Swiss Federal Statistical Office (2014). 


\section{Appendix}

Table A.1: Distribution of selected covariates across subsamples

\begin{tabular}{|c|c|c|c|c|c|}
\hline & & Cohort & & CVET stu & lents \\
\hline & & & $1+$ year & $2+$ years & have qualified \\
\hline & $\mathrm{N}$ & 3,324 & 857 & 672 & 442 \\
\hline Gender & girl & 48.92 & 45.39 & 47.62 & 46.38 \\
\hline Family structure & lives with both parents & 65.13 & 68.03 & 68.90 & 71.49 \\
\hline Language spoken at home & non French-speaker & 35.02 & 48.19 & 45.83 & 48.19 \\
\hline onallty groups & Suritrorlond & & & 0121 & \\
\hline & Switzerland & 69.80 & 57.99 & 61.31 & 63.35 \\
\hline & & 7.25 & 10.62 & 10.12 & 12.08 \\
\hline & Portugal & 9.42 & 12.72 & 12.05 & 11.31 \\
\hline & Balkans and Turkey & 3.37 & 7.47 & 6.85 & 6.56 \\
\hline & Rest of EU 27 & 3.22 & 2.33 & 1.79 & 0.68 \\
\hline & Rest of the World & 6.95 & 8.87 & 7.89 & 5.43 \\
\hline Socio-Economic Status & & & & & \\
\hline & white collars & 40.99 & 37.27 & 38.39 & 37.10 \\
\hline & managerial workers & 19.20 & 9.00 & 8.78 & 8.14 \\
\hline & self employed & 5.29 & 7.13 & 7.89 & 8.37 \\
\hline & blue collars & 29.63 & 40.07 & 39.14 & 41.18 \\
\hline & miscellaneous/NA & 4.89 & 6.54 & 5.80 & 5.20 \\
\hline
\end{tabular}

Data source: GSD Administrative data, 2003-2013.

Notes: 'CVET' stands for commercial vocational education and training.

The category ' $1+$ ' (' $2+$ ') refer to students with at least a (two) year(s) spent in CVET.

Table A.2: Probability to qualify for the subsample of students with at least two years of commercial VET: summary statistics

\begin{tabular}{lllll}
\hline & & Mean & Std. Dev. & Observations \\
\hline Total & overall & 0.127 & 0.333 & $\mathrm{~N}=4405$ \\
\hline Sources of variability & & & & N. of ids $=672$ \\
& between & & 0.079 & \\
& within & & 0.321 & \\
\hline
\end{tabular}

Data source: GSD Administrative data, 2003-2013.

Notes: the average number of periods observed for each individual is 6.6. 